\title{
Validation of General Climate Models (GCMs) over Upper Blue Nile River Basin, Ethiopia
}

\author{
Andualem Shigute Bokke ${ }^{1}$, Meron Teferi Taye ${ }^{2}$, Patrick Willems ${ }^{2}$, Shimelis Asefu Siyoum1 \\ ${ }^{1}$ Department of Hydraulic and Water Resources Engineering, Jimma Institute of Technology, Jimma University, \\ Jimma, Ethiopia \\ ${ }^{2}$ Hydraulics Division, Katholieke Universiteit Leuven, Leuven, Belgium \\ Email: *etuandu@gmail.com
}

How to cite this paper: Bokke, A.S., Taye, M.T., Willems, P. and Siyoum, S.A. (2017) Validation of General Climate Models (GCMs) over Upper Blue Nile River Basin, Ethiopia. Atmospheric and Climate Sciences, 7, 65-75.

http://dx.doi.org/10.4236/acs.2017.71006

Received: October 12, 2016

Accepted: January 16, 2017

Published: January 19, 2017

Copyright (C) 2017 by authors and Scientific Research Publishing Inc. This work is licensed under the Creative Commons Attribution International License (CC BY 4.0).

http://creativecommons.org/licenses/by/4.0/

(c) (†) Open Access

\begin{abstract}
Potential of climate change impact assessment on hydrology and water resources of rivers is increasing from time to time due to its importance for water resources planning and management in the future. In order to carry out climate change impact studies, using General Climate Models (GCM) is a common practice and before using any of these models, it is essential to validate the models for the selected study area. Blue Nile River is one of the most sensitive rivers towards climate change impacts. The main source of Blue Nile River is Lake Tana where the two adjacent tributary rivers, Ribb \& Gumera, are located and the main object of this paper is validation of current 15 GCM outputs (IPCC-AR5) over these two rivers using empirical quantile perturbation downscaling technique. The performance of the downscaled outputs of GCMs were evaluated using statistical indicators and graphical techniques for evapotranspiration, rainfall and temperature variables using observed daily meteorological datasets collected from five stations (Addis Zemen, Bahirdar, Debretabor, Woreta and Yifag) for the control period 1971-2000. Analysis results showed that the correlation coefficient of all models for mean monthly (MM) rainfall are $12 \%-45 \%$; and the Bias and RMSE $-46 \mathrm{~mm}$ to $+169 \mathrm{~mm}$ and $62 \mathrm{~mm}$ to $241 \mathrm{~mm}$, respectively. The Bias and RMSE for MM maximum temperature are $-2.5^{\circ} \mathrm{C}$ to $+35^{\circ} \mathrm{C}$; and $1{ }^{\circ} \mathrm{C}$ to $35^{\circ} \mathrm{C}$ whereas for MM minimum temperature $-6^{\circ} \mathrm{C}$ to $+22^{\circ} \mathrm{C}$ and $1.7^{\circ} \mathrm{C}$ to $23^{\circ} \mathrm{C}$, respectively. For the case of $\mathrm{MM}$ evapotranspiration, which is estimated using FAOPenman-Montheith equation, the Bias and RMSE values vary from $-35 \mathrm{~mm}$ to +10 $\mathrm{mm}$; and $+11 \mathrm{~mm}$ to $+36 \mathrm{~mm}$, respectively. The variation in the performance level of these models indicates that there is high uncertainty in the GCM outputs. Therefore, to use these GCM models for any climate change studies in the basin, careful selection has to be made.
\end{abstract}

\section{Keywords}

Blue Nile, Downscaling, GCM, Validation 


\section{Introduction}

Climate change caused by increasing concentrations of carbon dioxide and other trace gases in the atmosphere has been a major concern in recent decades. One of the major effects of climate change is likely to be alterations in hydrologic cycles and changes in water availability. Increased evaporation, combined with changes in precipitation, has the potential to affect runoff, the frequency and intensity of floods and droughts, soil moisture, and availability of water for irrigation and hydroelectric generation [1].

Currently, there are two distinct definitions for the phrase "climate change". These are from the Intergovernmental Panel on Climate Change (IPCC) and United Nations Framework Convention on Climate Change (UNFCCC). According to IPCC, climate change is defined as a change in the state of the climate that can be identified (e.g. using statistical tests) by changes in the mean and/or the variability of its properties and which persists for an extended period, typically decades or longer. It refers to any change in climate over time, whether due to natural variability or as a result of human activity, unlike that of UNFCCC that defines climate change as a change of climate that is attributed directly or indirectly to human activity that alters the composition of the global atmosphere in addition to natural climate variability observed over comparable time periods [2].

In the past decades, much attention is given to climate change impact studies on hydrology of rivers in the Nile basin [1] [3] [4] [5]. One of the important and sensitive basins towards climate change is the Blue Nile [6] [7] [8] where Ribb and Gumera sub basins are located. [5] used two conceptual hydrological models that were calibrated and used to carry out climate change impact assessment for two future Special Report on Emissions Scenario (SRES) A1B and B1 for 2050s using 17 GCMs for Nile basin. The result of the study has showed that there is unclear trend (like [9] and [10]) in Lake Tana sub-basin for projected flows (mean and high/low) and this is mainly attributed to Global Climate Models (GCMs) uncertainty.

[1] also demonstrates in the period 1980-2000 and 2080-2100 fifteen GCMs do not show consistent and statistically significant differences in total precipitation. Hence, carrying out additional studies may provide better understanding of the impact of climate change on the hydrologic cycle of these sub-basins with the current GCMs outputs produced for IPCC Assessment Report 5 (AR5).

The investigation of [1] on climate change impact on agricultural water resources variability in the Lake Tana sub-basin in using 15 GCM models shows that there is an increase in temperature around $2^{\circ} \mathrm{C}-5^{\circ} \mathrm{C}$ for the period $2080-2100$. Regarding the future precipitation, according to this study, it remains unclear because of both increasing and decreasing projection of precipitation. Therefore, it is difficult to provide strong conclusions on the future trend of precipitation in the region.

Moreover, it is important to study the impact of climate change on the extreme flows of the sub catchments. This is an important aspect since flooding is frequently caused by the two rivers at the downstream of their catchments, especially on Fogera flood plain located in the catchment. It is well documented that Fogera flood plain frequently floods due to the two rivers and backflow from Lake Tana [11] [12] [13]. The main inputs to climate change impact studies are climate variables from GCM. Before using 
GCM models for any climate change studies, it is important to validate their performance over the selected study area.

Most of the studies conducted on validation of GCM models over Blue Nile River are based on previous version of IPCC Assessment Report 4 (AR4) where as this study is based on the current IPCC product of Assessment Report 5 (AR5). The two Assessment Reports have different GCM products having different scenarios. GCM products from these reports are expected to have different performance levels over Blue Nile Catchment as well. Therefore, the main objectives of this study is validation of selected 15 GCMs from IPCC-AR5 and identify better performing models so as to use them for further climate change studies in the catchment.

\section{Materials and Methods}

\subsection{Description of the Study Area}

Ribb-Gumara sub-basin, drained by Ribb and Gumara Rivers, is located between $11^{\circ} 30^{\prime} \mathrm{N}$ and $12^{\circ} 30^{\prime} \mathrm{N}$ latitude and $37^{\circ} 30^{\prime} \mathrm{E}$ and $38^{\circ} 30^{\prime} \mathrm{E}$ longitude. The elevation of this area ranges from $1755 \mathrm{~m}$ to $4103 \mathrm{~m}$. This sub-basin is part of the upper Blue Nile River basin and more particularly that of the Lake Tana basin located on the Northeastern side of Lake Tana.

It has an area of about $3000 \mathrm{~km}^{2}\left(\right.$ Gumera $=1400 \mathrm{~km}^{2}$ and $\mathrm{Ribb}=1600 \mathrm{~km}^{2}$ ). Fogera district, which has an area of $1110 \mathrm{~km}^{2}$, totally lies in this catchment. This district is found in the downstream part of the catchment where Ribb and Gumara Rivers join to Lake Tana. Overflow of these rivers and back flow of Lake Tana frequently floods this districtmore than other districts in the sub-basin. These rivers have their sources in a mountainous area and in their lower reaches and flow through a large flat to very gentle sloping plain, which is exposed to severe flooding. The total annual rainfall ranges from about 1100 - $1530 \mathrm{~mm}$ /year. The spatial distribution of rainfall showed that eastern and central parts of the district receive highest rainfall while the northern portion receives the lowest. The seasonal rainfall has a monomodal distribution with the main rainy season being from June to September and peaking in July. The dry period is from October to April. The mean monthly temperature of the area is about $19^{\circ} \mathrm{C}$, monthly mean maximum temperature is about $27.3^{\circ} \mathrm{C}$, and monthly mean minimum temperature is $11.5^{\circ} \mathrm{C}$. Climate of the region is tropical highland monsoon. Land use map classification of 2000 shows that there are seven different land use classes; and the most dominant land use in the Ribb-Gumera catchments is agricultural land use.

\subsection{Data}

In this study two types of datasets were used: observed and GCM outputs. The historical period selected is 1971-2000. The meteorological variables included in the study were maximum and minimum temperature; rainfall and evapotranspiration.

The observed meteorological data, rainfall and temperature, recorded at five stations were used for evaluation of the GCMs for the study period selected. Out of the available meteorological stations in and around the catchments, four rainfall stations and one temperature station were selected. The location and name of the meteorological stations used in this study are given on Table 1. 
Table 1. Name and location of meteorological stations used for the study.

\begin{tabular}{cccc}
\hline NAME OF STATIONS & $\mathbf{X}(\mathrm{m})$ & $\mathrm{Y}(\mathrm{m})$ & ELEVATION $(\mathrm{m})$ \\
\hline ADDISZEMEN & 377,036 & $1,340,078$ & 2105 \\
BAHIRDAR & $3,776,188$ & $1,171,600$ & 1800 \\
DEBRETABOR & 394,371 & $1,317,892$ & 2314 \\
WORETA & 356,257 & $1,319,157$ & 1799 \\
YIFAG & 360,685 & $1,334,620$ & 1838 \\
\hline
\end{tabular}

The resolution of the GCM products used in this study ranges from $1.112^{\circ} \times 1.125^{\circ}$ up to $2.784^{\circ} \times 2.8125^{\circ}$, where $1^{\circ} \times 1^{\circ}$ represents a grid size of approximately $101 \mathrm{~km} \times$ $101 \mathrm{~km}$. The name of GCM models, developers and corresponding resolutions are given on Table 2.

\subsection{GCM Models Performance Evaluation}

The performances of 15 GCM models were evaluated by both statistical indicators and graphical techniques. The statistics used for evaluation were root mean square error (RMSE), bias and correlation coefficient; and the corresponding formulas for each of these statistics used are shown in equations 1,2 and 3. Using graphical techniques, 15 GCMs (control period) were compared with observed rainfall, maximum temperature, minimum temperature and evapotranspiration. The evapotranspiration used here was estimated using FAO-Penman-Montheith equation and the input variables used are minimum and maximum temperature for both observed and control periods.

$$
\begin{gathered}
\text { RMSE }=\sqrt{\frac{1}{n} \sum(M-O)^{2}} \\
\text { Bias }=\frac{1}{n} \sum(M-O) \\
\text { Correlation }(r)=r_{M O} / r_{M} \cdot r_{O}
\end{gathered}
$$

where: $M$ : is control period (GCMs) time series,

$O$ : is corresponding time series of observation of the same physical quantity,

(Rainfall, Temperature and Evapotranspiration),

$r_{M O}$ : Covariance between control period (GCMs) and observation,

$r_{M}$ : Standard deviation of control period (GCMs),

$r_{O}$ : Standard deviation of observation.

\section{Results and Discussion}

\subsection{Rainfall}

After analysis of the areal rainfall of the Ribb-Gumera catchment, it is found that nearly all the models except cnrm-cm5 under estimated the seasonal rainfall during the main rainy season (June-September) and also some models didn't captured the peak rainy month (the models showed it is August but the observed data shows it is July). The other point is that during dry season all the models over estimated as compared to the observed data. Two extreme performances of these models is clearly observed on the 
Table 2. GCM models, name of developers and resolutions (Lat. $\times$ Lon.).

\begin{tabular}{ccc}
\hline Model name & Developed by & Resolution (lat. $\times$ lon.) \\
\hline BCC-CSM1.1m & China & $1.112^{\circ} \times 1.125^{\circ}$ \\
CMCC-CMS & Europe & $1.861^{\circ} \times 1.875^{\circ}$ \\
CNRM-CM5 & France & $1.397^{\circ} \times 1.406^{\circ}$ \\
MIROC5 & Japan & $1.397^{\circ} \times 1.406^{\circ}$ \\
MRI-CGCM3 & Japan & $1.119^{\circ} \times 1.125^{\circ}$ \\
CSIRO-MK3.6.0 & Australia & $1.861^{\circ} \times 1.875^{\circ}$ \\
HadGEM2-CC & UK & $1.25^{\circ} \times 1.875^{\circ}$ \\
HadGEM2-ES & UK & $1.25^{\circ} \times 1.875^{\circ}$ \\
INMCM4 & Russia & $1.5^{\circ} \times 2^{\circ}$ \\
IPSL-CM5A-MR & France & $1.268^{\circ} \times 2.6^{\circ}$ \\
MPI-ESM-MR & Germany & $1.861^{\circ} \times 1.875^{\circ}$ \\
MPI-ESM-LR & Germany & $1.861^{\circ} \times 1.875^{\circ}$ \\
BCC-CSM1.1 & China & $2.784^{\circ} \times 2.8125^{\circ}$ \\
CanESM2 & Canada & $2.784^{\circ} \times 2.8125^{\circ}$ \\
\hline
\end{tabular}

Source: [15].

seasonal rainfall variation. The two models (lpsl-cm5a and bcc-csm1.1) very poorly performed where as CanESM2, mpi-esm-mr and mpi-esm-lr performed better as compared to the observed data with regard to seasonal rainfall. But cnrm- $\mathrm{cm} 5$ showed unexpected overestimation of rainfall during the main rainy season (June-September). The seasonal rainfall variation for all the models with measured dataset is showed on Figure 1.

The graph for RMSE and BIAS are shown on Figure 2 and Figure 3, respectively. The BIAS and RMSE values ranges $(-80-169 \mathrm{~mm} / \mathrm{month})$ and $(62-241 \mathrm{~mm} / \mathrm{month})$, respectively. The correlation coefficient between the observed rainfall time series and the control period GCMs were computed; and all of the correlation coefficient values for the models are less than 0.5; and the maximum and minimum values are 0.45 and 0.12 for micoc 5 and HadGEM2-CC, respectively and these shows that all the models are not fully trusted to use for climate change impact studies.

Besides the statistics used for GCM models' performance evaluation, frequency quantile analysis (as shown on Figure 4) has been done to check the models' performance for extreme events at daily scale. The analysis is based on ranked daily rainfall values of both control period and observed areal rainfall time series, where the corresponding values are compared for the same empirical return period. The empirical return period is calculated using the formula in the equation 4 below.

$$
T=n / r
$$

where: $T$ : is return period in years;

$n$ : is total number of years the data taken from and

$r$. is the rank number of daily rainfall data.

The analysis showed that for all return periods six models over estimated and nine models under estimated the quantile rainfall but all the models captured the pattern of 


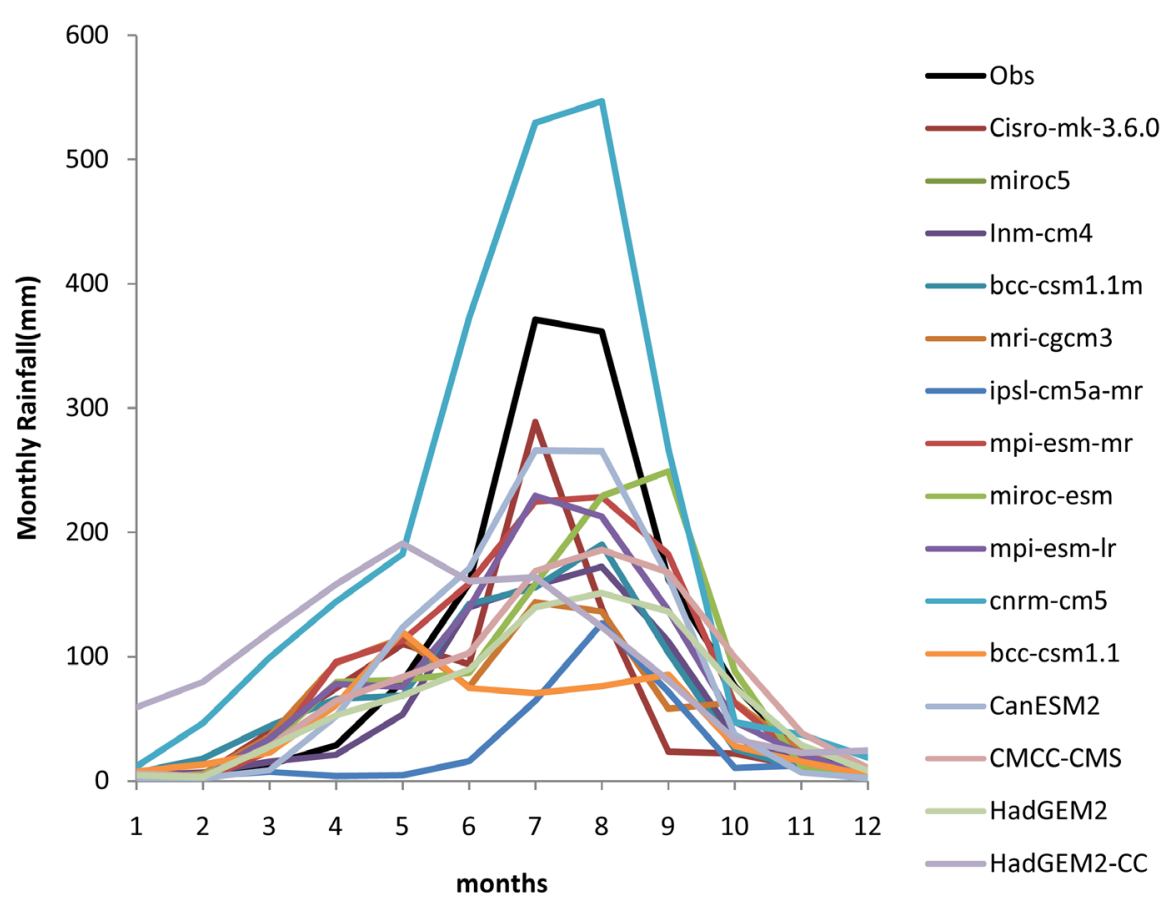

Figure 1. GCM model performance evaluation for Seasonal rainfall over the study area.

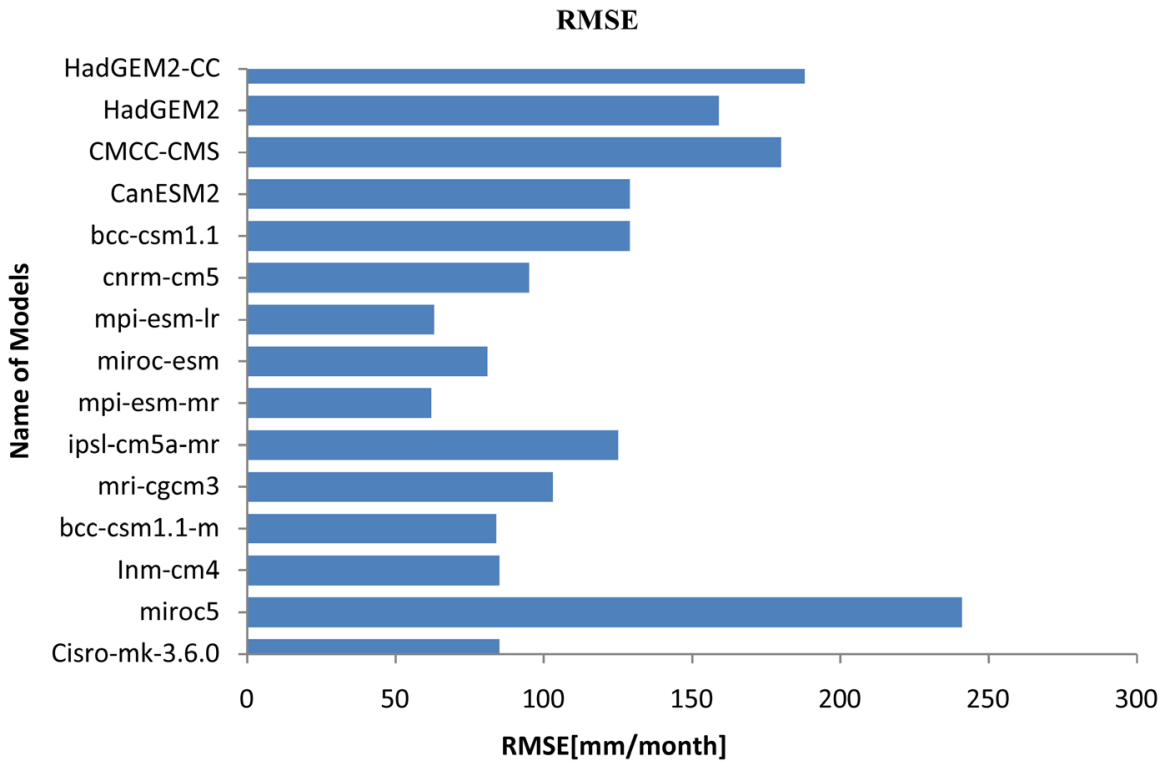

Figure 2. GCM model performance evaluation for rainfall using RMSE.

observed data nearly in good way.

Finally it is found that the best model for rainfall analysis among 15 selected models is mpi-esm-mr based both least BIAS ( $-15 \mathrm{~mm} / \mathrm{month}$ ) and least RMSE (62 mm/ month); and with regard to capturing seasonal rainfall over the study area it is mpiesm-lr model.

\subsection{Temperature}

The maximum and minimum mean monthly temperatures were analyzed for both the 


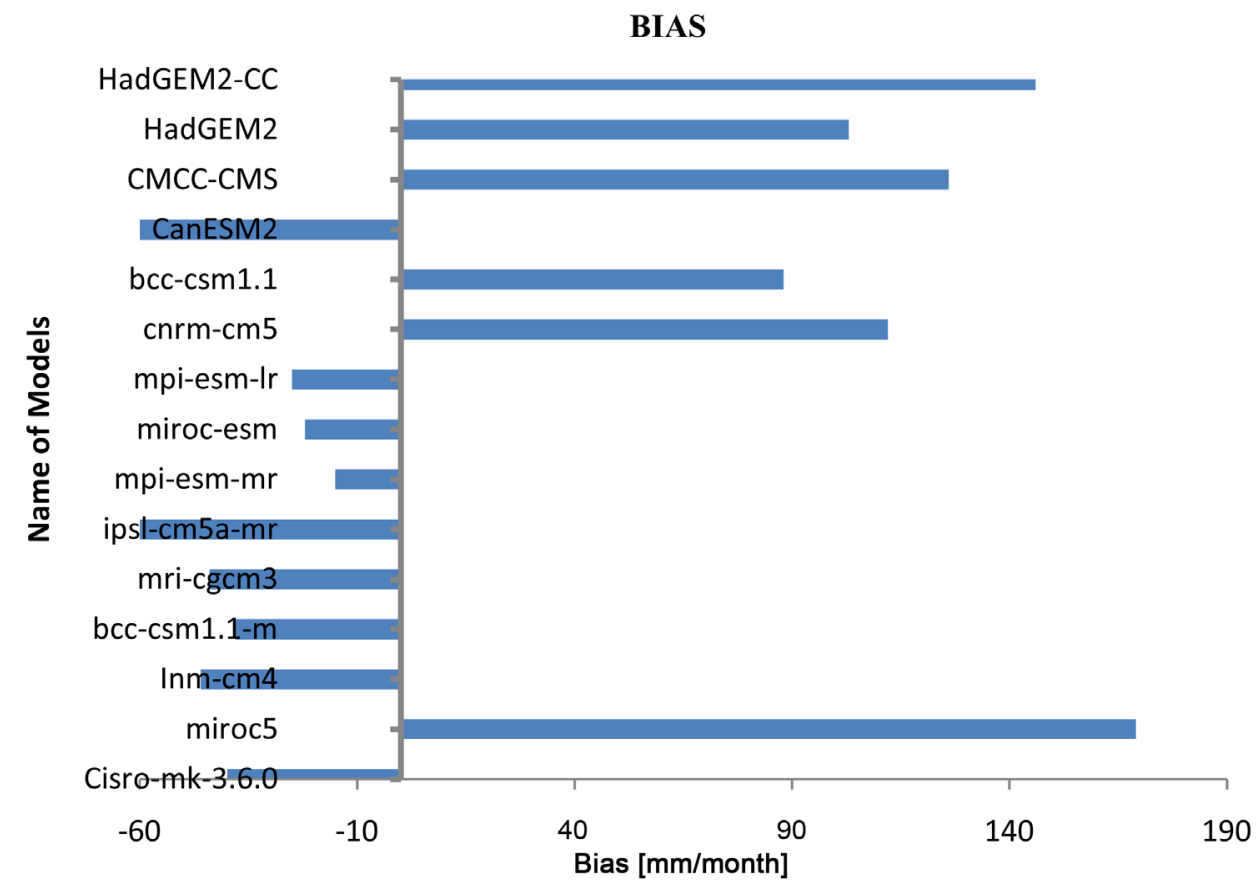

Figure 3. GCM models performance evaluation for rainfall using BIAS.

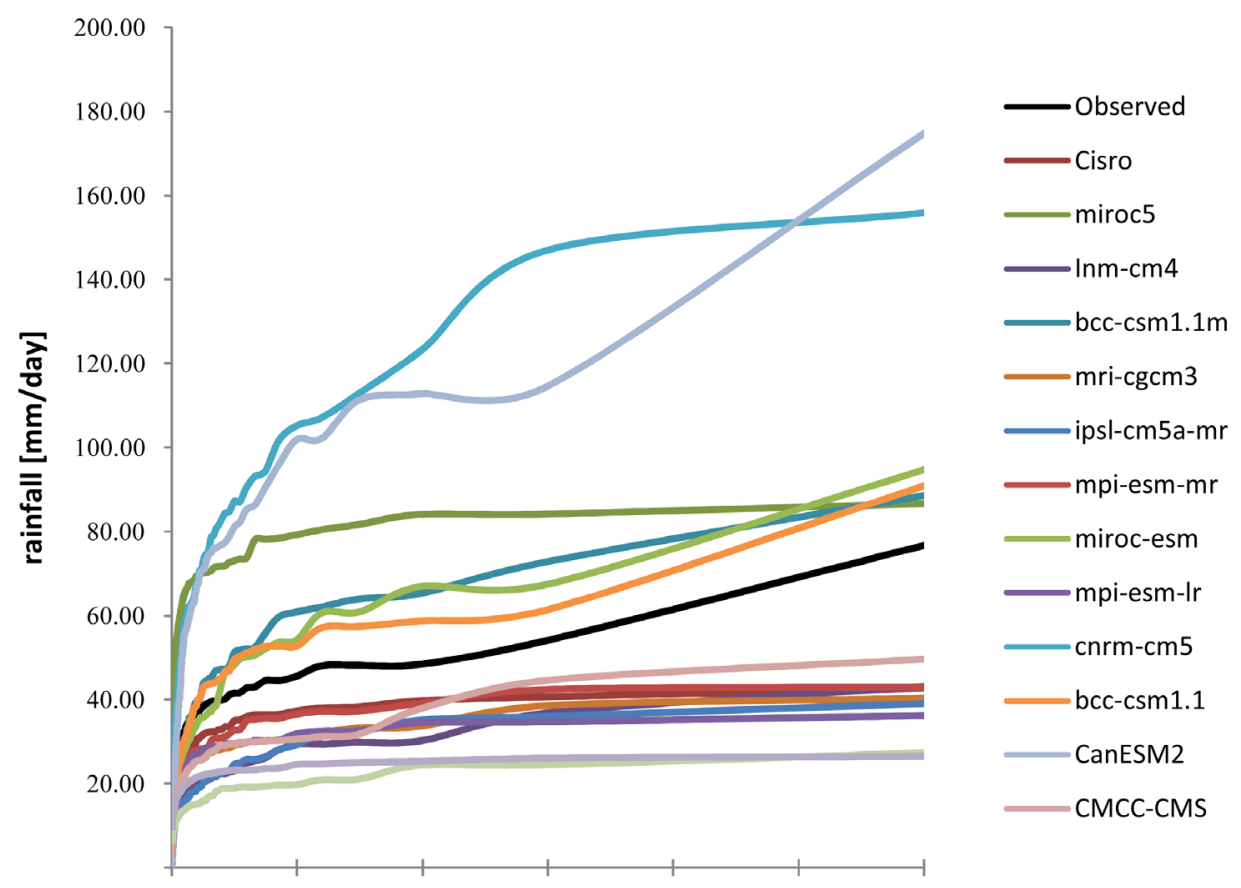

Figure 4. GCM models performance evaluation for rainfall using frequency quantile analysis.

GCMs and observed value, which is recorded at Bahirdar station for the period (19712000). The analysis shows that most of the models (12 models) overestimate the mean monthly minimum temperature and few of the models ( 3 models) underestimate; but almost all of the models captured the pattern except Inm-cm4, which showed unexpected pattern. The two GCM models ( $\mathrm{cnrm}-\mathrm{cm} 5$ and Inm-cm4) underestimated and the remaining 12 models overestimated the mean monthly maximum temperature val- 
ues. All of the models followed the pattern of the observation in nice way. Performance of these models is at different level for maximum and minimum temperature; and most of the models performed better for maximum temperature than minimum temperature. For both temperatures, the performance level was showed on Figure 5 and Figure 6.

\subsection{Evapotranspiration}

Using the maximum and minimum temperature as an input to Evapotranspiration

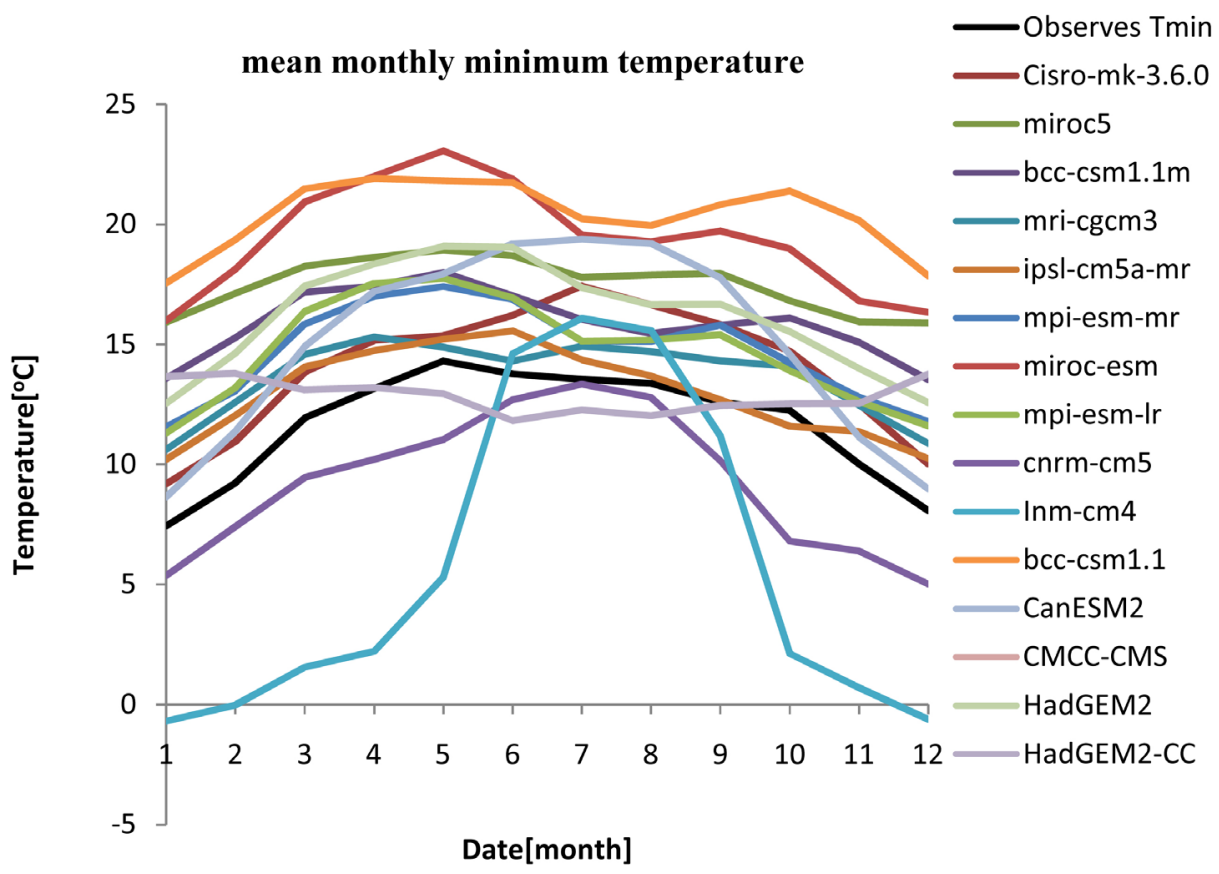

Figure 5. GCM model performance evaluation for average monthly minimum temperature.
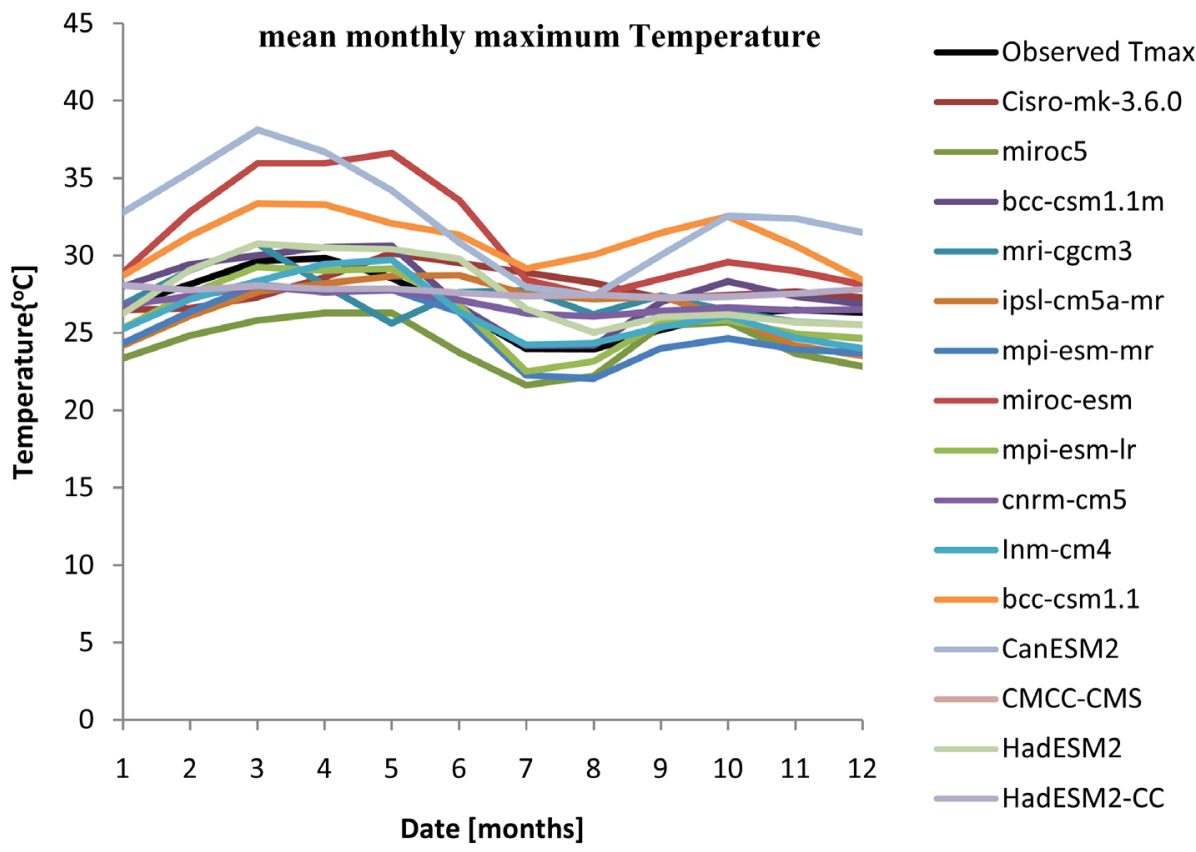

Figure 6. GCM models evaluation for average maximum monthly temperature. 


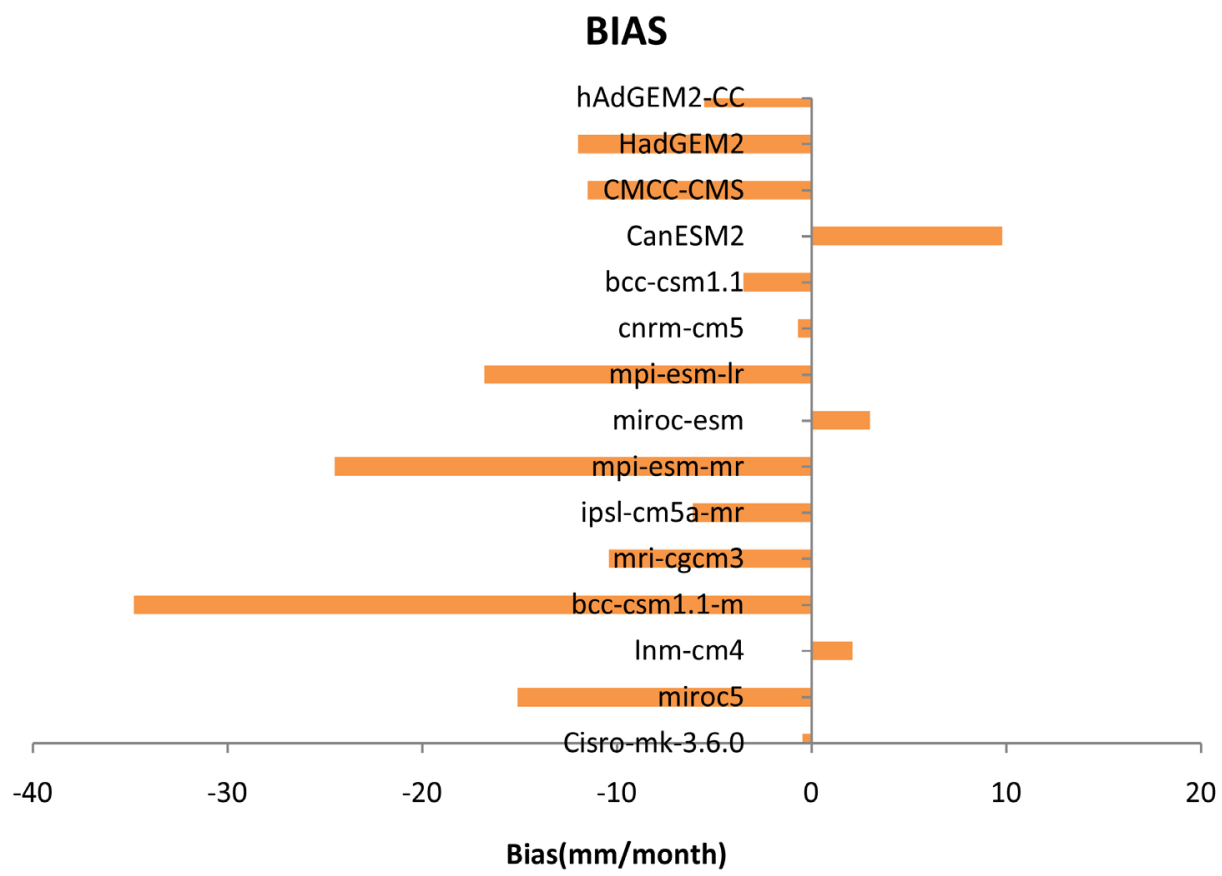

Figure 7. GCM models performance evaluation for ETo using BIAS.

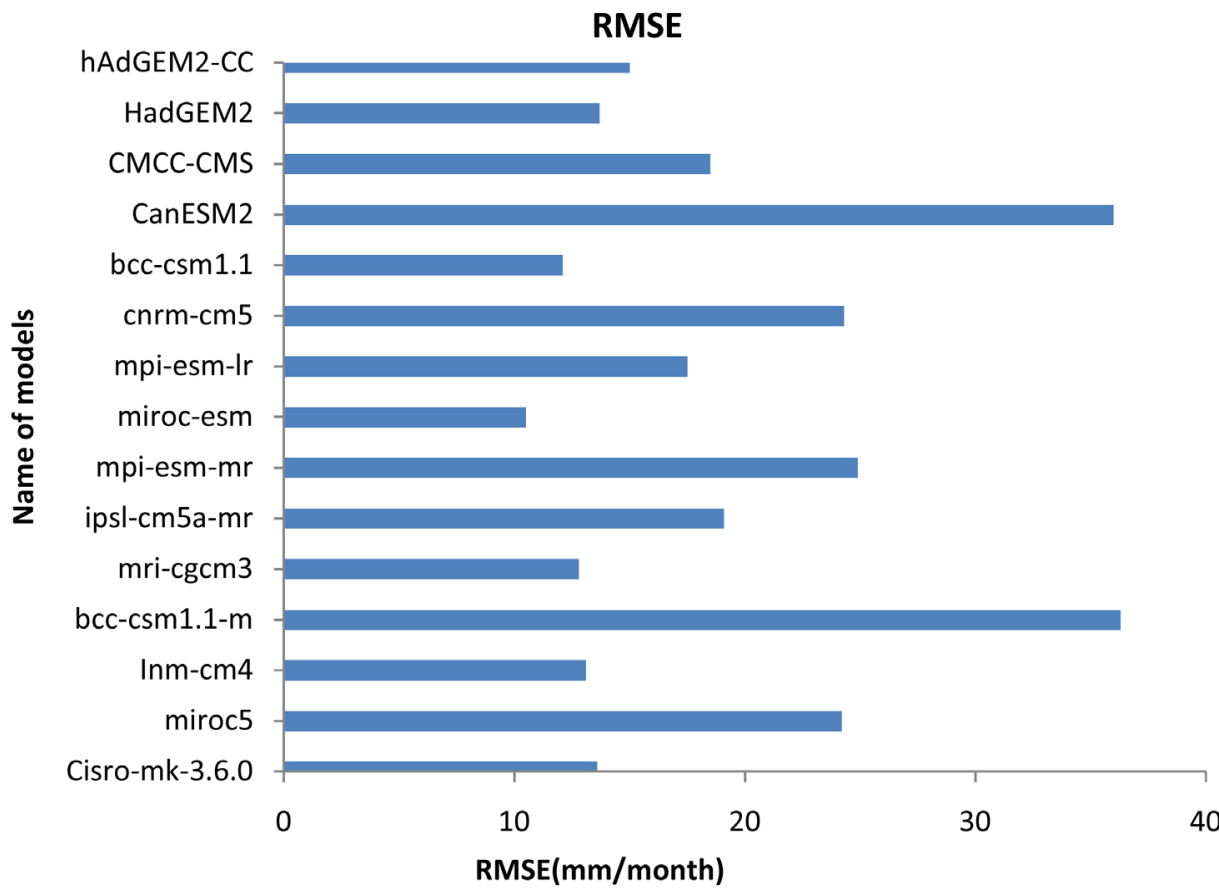

Figure 8. GCM models performance evaluation for ETo using RMSE.

which is developed based on FAO-Penman-Montheith equation [14], the evapotranspiration was estimated for the observation and the control period.

Due to lack of data for all required climatic inputs the FAO-Penman-Montheith method of estimating $\mathrm{ET}_{\mathrm{O}}$, with limited data option was applied in this study. The method estimates the other variables (radiation, wind speed, relative humidity, and air pressure) based on the observed maximum and minimum temperature and the geographic loca- 
tion of the catchment. As it can be seen from analysis result of BIAS \& RMSE for ETo estimation for the control period, Cisro-mk-3.6.0 has the least and bcc-ssm1.1-m has the highest negative BIAS among the models. With regard to RMSEmiroc-esm has the least and bcc-csm-1.1-m \& CanESM2 have the highest RMSE. The best performed model for ETo is miroc-esm and the least performed is bcc-csm-1.1-m. Evaluation of all the models for Evapotranspiration is shown on Figure 7 and Figure 8 for BIAS and RMSE, respectively.

\section{Conclusions}

The performances of the downscaled outputs of 14 GCMs were evaluated using statistical indicators (BIAS, RMSE \& correlation coefficient.) and graphical techniques for evapotranspiration, rainfall and temperature variables using observed daily meteorological datasets (maximum temperature, minimum temperature and rainfall) collected from five meteorological stations (Addis Zemen, Debretabor, Woreta and Yifag) for the control period (1971-2000).

Analysis results showed that the correlation coefficient of all models for mean monthly rainfall ranges between $12 \%$ to $45 \%$; and the Bias and RMSE varies from $-46 \mathrm{~mm}$ to $+169 \mathrm{~mm}$ and $62 \mathrm{~mm}$ to $241 \mathrm{~mm}$, respectively. The Bias and RMSE are in the range of $-2.5^{\circ} \mathrm{C}$ to $+35^{\circ} \mathrm{C}$ and $1^{\circ} \mathrm{C}$ to $35^{\circ} \mathrm{C}$ for mean monthly maximum temperature whereas for mean monthly minimum temperature it is in the range of $-6^{\circ} \mathrm{C}$ to $+22^{\circ} \mathrm{C}$ and $1.7^{\circ} \mathrm{C}$ to $23^{\circ} \mathrm{C}$, respectively. For the case of mean monthly evapotranspiration, which is estimated using FAO-Penman-Montheith equation, the Bias and RMSE values vary from $-35 \mathrm{~mm}$ to $+10 \mathrm{~mm}$ and $11 \mathrm{~mm}$ to $36 \mathrm{~mm}$, respectively.

The variation in the performance level of these models indicates that there is high uncertainty in the GCMs outputs. As it is seen from the correlation coefficient for rainfall $(0.12-0.45)$ which is less than 0.5 , all the models cannot be fully relayed on for climate change impact studies with regard to rainfall. Similarly, this is also true for the other variables as it is can be seen from BIAS and RMSE values which are large. The performance variation among the models also demonstrates that there is high uncertainty in the GCM outputs. The other finding of this study is that a given model may perform well for a given meteorological variable and may not perform well for another meteorological variable; and also making conclusion about performance of a given model based a single evaluation statistics (BIAS, RMSE, r) or single graphical evaluation technique may miss lead to wrong conclusion. For example according to this study the best performed models for rainfall are mpi-esm-mr and mpi-esm-lr where as for evapotranspiration it is miroc-esm. Therefore, to use these GCM models for climate change studies in the basin, careful selection has to be made based on different performance evaluation techniques.

\section{Acknowledgements}

The researcher would like to thank the Belgian government for supporting this study through ICP masters study program and also KU Leuven hydraulics laboratory for supporting downloading of large size GCM models in their laboratory. I also like to say thank you very much for my wife Etabezahu Tadese for her encouraging words and 
continuous support in my life.

\section{References}

[1] Setegn, S.G., David, R., Assefa, M.M., Bijan, D., Ragahavan, S. and Anders, W. (2011) Climate Change Impact on Agricultural Water Resources Variability in the Northern Highlands of Ethiopia. Nile River Basin Hydrology, Climate and Water Use. Springer, USA.

[2] Intergovernmental Panel on Climate Change (IPCC) (2007) Climate Change. Synthesis Report.

[3] Hamlet, A.F. and Lettenmaier, D.P. (1999) Effects of Climate Change on Hydrology and Water Resources in the Columbia River Basin. Journal of the American Water Resources Association, 35.

[4] Christensen, N.S., Wood, A.W., Voisin, N., Lettenmaier, D.D. and Palmer, R.N. (2004) The Effects of Climate Change on the Hydrology and Water Resources of the Colorado River Basin. Climatic Change, 62, 337-363. https://doi.org/10.1023/B:CLIM.0000013684.13621.1f

[5] Taye, M.T., Ntegeka, V., Ogiramoi, N.P. and Willems, P. (2011) Assessment of Climate Change Impact on Hydrological Extremes in Two Source Regions of the Nile River Basin. Hydrology and Earth System Sciences, 15, 209-222. https://doi.org/10.5194/hess-15-209-2011

[6] Kim, U. and Kaluarachchi, J.J. (2009) Climate Change Impacts on Water Resources in the Upper Blue Nile River Basin, Ethiopia. Journal of the American Water Resources Association, 45, 1361-1378. https://doi.org/10.1111/j.1752-1688.2009.00369.x

[7] Eman, S.A., Soliman, Sayed, M.A. and Marc, J. (2009) Impact Assessment of Future Climate Change for the Blue Nile Basin, Using a RCM Nested in a GCM. Nile Basin Water Engineering Scientific Magazine, 2.

[8] Di Baldasarre, G., Elshamy, M., Van Griensven, A., Soliman, E., Kigobe, M., Ndomba, P., Mutemi, J., Mutua, F., Moges, S., Xuan, Y.Q., Solomatine, D. and Uhlenbrook, S. (2011) A Critical Discussion of Recent Studies Evaluating the Impacts of Climate Change on WaterResources in the Nile Basin. Nile Basin Water Science \& Engineering Journal, 4.

[9] Elshamy, M.E., Seierstad, I.A. and Sorteberg, A. (2009) Impacts of Climate Change on Blue Nile Flows Using Bias-Corrected GCM Scenarios. Hydrology and Earth System Sciences, 13, 551-565. https://doi.org/10.5194/hess-13-551-2009

[10] Sead, A. (2010) Analysis of the Impact of Land Use Change and Climate Change on the Flows in the Blue Nile River Using SWAT. Unpublished Master's Thesis, KU Leuven, Belgium.

[11] Amsalu, W. (2011) Flood Modeling Using 2D Hydrodynamic Model in the Fogera Flood Plain. Unpublished Master's Thesis, Addis Ababa University, Ethiopia.

[12] Woldegiorgis, B. (2013) Impacts of Land Use Change on Hydrological Extremes in RibbGumara Catchments. Unpublished Master's Thesis, KU Leuven, Belgium.

[13] Gashaw, W. and Legesse, D. (2011) Flood Hazard and Risk Assessment Using GIS and Remote Sensing in Fogera Woreda, Northwest Ethiopia. Nile River Basin Hydrology, Climate and Water Use, 1.

[14] Raes, D. (2009) Evapotranspiration Calculator User Manual. Food and Agriculture Organization (FAO) of the United Nations Land and Water Division, Italy.

[15] Chen, H., Sun, J. and Chen, X. (2013) Projection and Uncertainty Analysis of Global Precipitation-Related Extremes using CMIP5 Models. International Journal of Climatology. 
Submit or recommend next manuscript to SCIRP and we will provide best service for you:

Accepting pre-submission inquiries through Email, Facebook, LinkedIn, Twitter, etc. A wide selection of journals (inclusive of 9 subjects, more than 200 journals) Providing 24-hour high-quality service

User-friendly online submission system

Fair and swift peer-review system

Efficient typesetting and proofreading procedure

Display of the result of downloads and visits, as well as the number of cited articles Maximum dissemination of your research work

Submit your manuscript at: http://papersubmission.scirp.org/

Or contact acs@scirp.org 